\title{
DETERMINATION OF TRICLABENDAZOLE IN CATTLE PLASMA AS ITS SULPHOXIDE AND SULPHONE METABOLITES BY ROTATING DISK SORPTIVE EXTRACTION COMBINED WITH HIGH-PERFORMANCE LIQUID CHROMATOGRAPHY AND ITS APPLICATION TO PHARMACOKINETIC STUDIES
}

\author{
ALEJANDRO CAÑAS-MÜLLER ${ }^{1,2}$, MARCIAL VARGAS DEL CAMPO², PABLO RICHTER ${ }^{1, *}$ \\ ${ }^{I}$ Department of Inorganic and Analytical Chemistry, Faculty of Chemical and Pharmaceutical Sciences, University of Chile, P.O. Box 233, Santiago, Chile. \\ ${ }^{2}$ Veterquímica S.A. Camino a Lonquén 10.387, Santiago, Chile.
}

\begin{abstract}
In this study, a new method for determination of triclabendazole (TCB) as its main metabolites, triclabendazole sulfoxide (TCB-SO) and triclabendazole sulfone (TCB-SO ${ }_{2}$ ) in animal plasma was developed. TCB is widely used as antiparasitic in the veterinary industry. Rotating disk sorptive extraction (RDSE) was the selected sample preparation technique for extraction/clean up of the compounds from the samples followed by high performance liquid chromatography coupled to diode array detection (HPLC-DAD) for quantification.

Optimization of physicochemical variables was performed using a multivariate experimental design. Following the recommendations given in the Veterinary International Conference on Harmonization guides (VICH GL02 and VICH GL49), the validation of the method was performed, given rise to improved analytical features compared with those provided by other methods based on solid phase extraction (SPE). Linearity $(r>0.99)$ was achieved for both compounds when calibration was performed not only in standard solutions but also in animal spiked plasma. Selectivity, defined as the response ratio between blank and analyte at the limit of quantification, was $11.8 \%$ and $3.4 \%$ for TCB-SO and TCB-SO ${ }_{2}$, respectively. Accuracy and precision, expressed in percentage, were always lower than $-16.7 \%$ and $8.1 \%$, respectively. Eco-efficiency was quantitatively assessed indicating that the method is an excellent green method.

The proposed analytical method was applied to the determination of the pharmacokinetic of two commercial products of TCB in cattle plasma after oral administration.

The good analytical performance, eco-efficiency and economy, make the method interesting for alternative use in routine laboratories.
\end{abstract}

Keywords: Triclabendazole; triclabendazole sulfoxide; triclabendazole sulfone; cattle plasma; Rotating disk sorptive extraction; HPLC.

\section{INTRODUCTION}

Triclabendazole (6-chloro-5- (2,3-dichloro phenoxy) -2-methyl-tiobenzimidazole; TCB) (Fig. 1) is an anthelmintic antiparasitic belonging to the family of benzimidazoles, which are highly effective for the treatment of the mature and immature forms of Fasciola hepatica and Fasciola gigantica in all ruminant species. ${ }^{1}$ This drug is widely used for the treatment of this kind of disease in beef cattle.

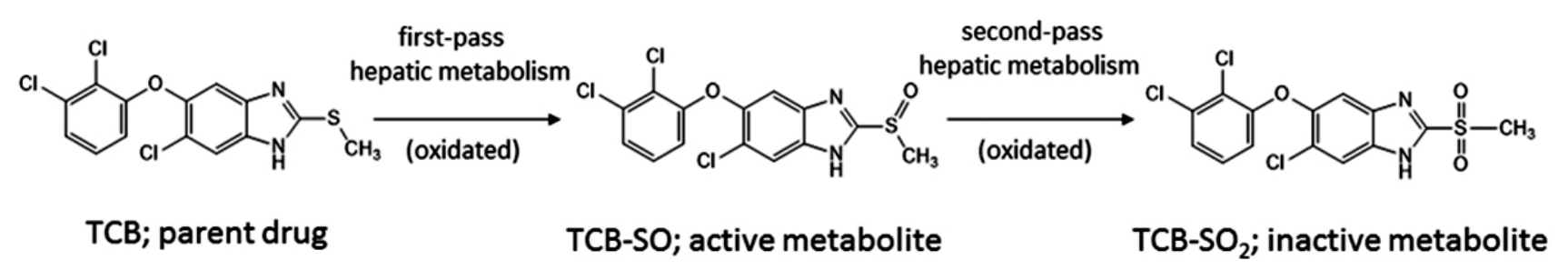

Fig. 1. Scheme for the hepatic metabolism of triclablendazol (TCB) to triclabendazol-sulphoxide (TCB-SO) and triclabendazol-sulphone (TCB-SO ${ }_{2}$ ) metabolites.

The absorption, distribution, metabolism and excretion of TCB have been extensively studied and similar processes have been observed in both cattle and sheep. ${ }^{1}$ After oral administration, a portion of the TCB is absorbed in the gastrointestinal tract, and then, it is rapidly oxidized by liver enzymes to triclabendazole sulfoxide (TCB-SO), followed by slow oxidation to triclabendazole sulfone species (TCB-SO $)_{2}$ (Fig. 1). Despite its activity, TCB is practically absent in plasma, however, after distribution, its active metabolite TCB-SO is the responsible of the fasciolicide activity; meanwhile TCB-SO2 is an inactive metabolite that accounts for the drug elimination stage., ${ }^{2,3}$ The antiparasitic activity of the TCB is time dependent. Its therapeutic effects occur when the administered product maintains effective concentrations of TCB and TCB-SO at the location of Fasciola hepatica. ${ }^{1,4}$

A number of analytical methods have been described to determine TCB and its metabolites in different matrices. ${ }^{5-12}$ The simultaneous determination of TCB and its metabolites has been reported in bovine and goat tissues by using an extraction of analytes from the tissues with acetonitrile, and then crude extracts are subjected to liquid-liquid extraction with n-hexane. ${ }^{9,10} \mathrm{~A}$ traditional liquid-liquid extraction has also been described for separation/ determination of TCB from spiked human plasma using ethyl acetate. ${ }^{11}$ Greener methodologies based on solid phase extraction (SPE) have also been proposed for preparation of samples containing anthelmintics. For instance, SPE using hydrophilic-lipophilic polymeric based sorbent (Oasis HLB) was proposed to pre-concentrate the analytes from surface water samples and, considering the low concentration level of the analytes in the samples, ultra high performance liquid chromatography coupled to quadrupole linear ion trap tandem mass spectrometry was applied for quantification. ${ }^{12}$

Taking into account the importance of the pharmacological activity of TCB and its metabolites and the distribution and presence of each of the species in plasma, it is important to develop analytical strategies to measure the metabolites in this matrix as a direct indicator of the efficiency and pharmacokinetic assessment of the product administered, which is in turn the main tool to assess the bioequivalence of pharmaceutical products. Currently the determination of TCB in animal plasma has been performed by solid phase extraction (SPE) of its metabolites using $\mathrm{C}_{18}$ cartridges, followed by HPLC. ${ }^{5-8}$

Rotating disk sorptive extraction technique (RDSE) is a low-cost alternative microextraction technique, which has been recently described by our team for a simple preparation of environmental and biological samples. The extraction device used in RDSE contains a cavity into which the sorptive phase is loaded to extract the analyte from complex samples. ${ }^{13,14}$ By following this approach, in this work, we demonstrated that this extraction platform is equally applicable for determination of TCB as its metabolites sulphone and sulphoxide in cattle plasma. This method results in a greener and simpler 
alternative compared with methods based on SPE. ${ }^{5-8}$ In addition, the extraction device is reusable and easily built in the laboratory.

\section{MATERIALS AND METHODS}

\section{Reagents}

Water from a Millipore-Q Plus water system (Billerica, MA) was used throughout. TCB-SO (99.6\% purity) and TCB-SO2 (99.1\% purity) were provided by Sigma-Aldrich (Milwaukee, WI, USA). A stock standard solution of the analyte of $1000 \mu \mathrm{gmL}^{-1}$ was prepared in methanol and were stable for at least 2 month at $-18^{\circ} \mathrm{C}$. Intermediate standard solutions of $10 \mu \mathrm{gmL}^{-1}$ were prepared by dilution with methanol and were stable for at least one week at $4^{\circ} \mathrm{C}$. The powdered extraction sorbent Oasis HLB (60 $\mu \mathrm{m}$ particle size) was obtained from cartridges provided by Waters (Milford, MA, USA). Octadecyl $\mathrm{C}_{18}$ provided by UCT (United Chemical Technologies, Bristol, England) was also assessed as sorptive phase. All solvents were HPLC grade and obtained from Merck (Darmstadt, Germany).

\section{Instruments and apparatus}

The rotating disks were driven using a 10-position magnetic stirrer, and in this experiment, an MS 52M (Jeio Tech, Korea) was used. Quantification was performed using a LaChrom Elite ${ }^{\circledR}$ HPLC System (Hitachi, Tokyo, Japan) with a L-2450 diode array detector (DAD) (Hitachi) and a $\mathrm{C}_{18}$ HPLC column (250 $\mathrm{mm} \times 4.6 \mathrm{~mm} \times 5 \mu \mathrm{m}$, Waters).

Preparation of the rotating disks

The extraction device used in this study was a Teflon disk $(1.5 \mathrm{~cm}$ diameter $)$ containing an imbedded miniature magnetic stirring bar (Teflon-coated Micro Stir bar from VWR International). The disk has a cavity $\left(0.44 \mathrm{~cm}^{3}\right)$ on one of its surfaces in which $50 \mathrm{mg}$ of Oasis ${ }^{\mathrm{TM}}$ HLB sorbent was loaded. The cavity was covered with a fiberglass filter $(1.4 \mathrm{~cm}$ diameter, mean pore size $3 \mu \mathrm{m})$ and sealed with a Teflon ring. ${ }^{13}$

\section{Analytical procedure}

The scheme of the analytical procedure is shown in Fig. 2. Fifteen milliliters of phosphate buffer $(\mathrm{pH} 3 ; 10 \mathrm{mM})$ was poured into a $25 \mathrm{~mL}$ EPA vial, and a $400 \mu \mathrm{L}$ aliquot of cattle plasma sample was added. The previously conditioned disk was submerged in the sample and rotated at $2000 \mathrm{rpm}$ for 90 $\mathrm{min}$. After the extraction, the disk was placed into a $15 \mathrm{~mL}$ vial that contained $8 \mathrm{~mL}$ of acetone as the desorption solvent. The disk was stirred at $1400 \mathrm{rpm}$ for a desorption time of $60 \mathrm{~min}$. The solvent was then evaporated to dryness under a $\mathrm{N}_{2}$ stream, and the final extract was re-dissolved in $2 \mathrm{~mL}$ of the mobile phase. Ten samples were processed simultaneously by using a multi-position magnetic stirrer.

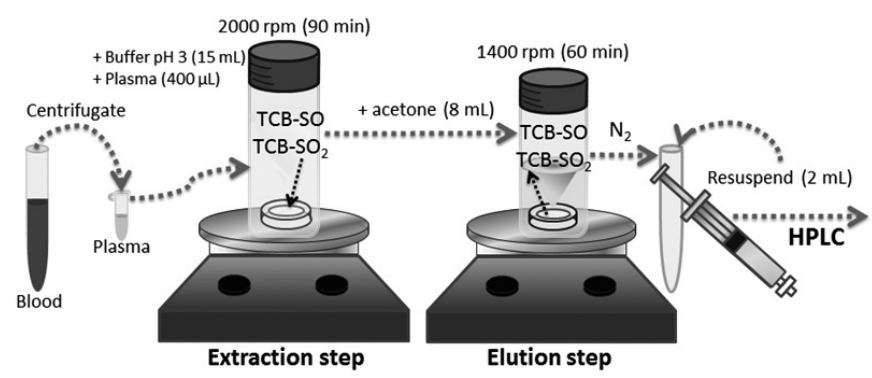

Fig. 2. RDSE methodology steps used for determination TCB-SO and $\mathrm{TCB}-\mathrm{SO}_{2}$ in cattle plasma.

The mobile phase consisted of a mixture of acetonitrile and water at a ratio of $1: 1(\mathrm{v} / \mathrm{v})$. The injection volume was $50 \mu \mathrm{L}$, the monitoring wavelength was $294 \mathrm{~nm}$, the oven temperature was at $25^{\circ} \mathrm{C}$, and the flow rate was $1.0 \mathrm{mLmin}^{-1}$.

The calibration curve for quantification was prepared using blank cattle plasma at a range of concentrations from $0.5-20 \mu \mathrm{gmL}^{-1}(\mathrm{n}=6$, each point in triplicate), corresponding to an appropriate range for a pharmacokinetic study in oral doses of $12 \mathrm{mgkg}^{-1}$. DAD)

Spectrum match was used for confirmation of analytes in samples (HPLC-

\section{Optimization of variables}

Plasma volume (or dilution factor of plasma into buffer) and $\mathrm{pH}$ were optimized using a central composite experimental design $(2 k+2 k+2)$ centered in the faces and with two centers. Sample volumes of 800,400 and $200 \mu \mathrm{L}$, equivalent to dilution factors of $2.5,5.0$ and 10.0 and $\mathrm{pH}$ of 3,4 and 5 were used. Other conditions for this study were $50 \mathrm{mg}$ of sorbent, extraction time of $90 \mathrm{~min}$ and rotation velocity of $2000 \mathrm{rpm}$. Blanks of cattle plasma were spiked at $2.5 \mu \mathrm{gmL}^{-1}$ of TCB-SO and TCB-SO ${ }_{2}$ for optimization of variables. Recoveries of both metabolites were used as response.

The optimized method was then validated following standard criteria established in VICH GL02 and VICH GL49, ${ }^{15,16}$ and the following analytical features were determined: linearity of standards, linearity of spikes, selectivity, detection limit, quantification limit, accuracy and precision.

\section{Animals and experimental design}

Twelve healthy and parasite-free cattles of the same age were used in this pharmacokinetic study. All cattles were male $(250 \pm 5 \mathrm{~kg})$. Before and during the study, the animals graze freely and were provided with drinking water. After seven days of acclimatization to the experimental conditions, the animals were housed in a collective farm for seven days of the study period. The frequency of sampling for pharmacokinetic is shown in Table 1. Animal experiments were performed in an approved ethical manner following the Guidelines of Good Clinical Practice. ${ }^{17}$ The cattles were weighed before administration of the drug, and the dose was adjusted accordingly. TCB was administered by oral route, in one single dose of $12 \mathrm{mgkg}^{-1}$ bodyweight of TCB formulation $\left(10 \%\right.$ oral Trisuvet Veterquímica ${ }^{\circ}$, Santiago, Chile) for six cattles $(\mathrm{n}=6)$. In parallel, for comparative purposes, a commercial formulation was administered to other six cattles $(n=6)$, to perform the pharmacokinetic study. Blank samples were taken from each cattle just before drug administration. The samples were centrifuged for $10 \mathrm{~min}(1.5 \mathrm{G})$, and the plasma samples were frozen $\left(-20^{\circ} \mathrm{C}\right)$ until analysis. All samples were analyzed within two weeks after the experiments were performed.

Table 1. Acquisition test samples for pharmacokinetic study $(\mathrm{n}=6)$.

\begin{tabular}{|c|c|c|c|c|c|c|c|}
\hline Day & 1 & 2 & 3 & 4 & 5 & 6 & 7 \\
\hline \multirow{5}{*}{ Hours } & 0 & 24 & 48 & 72 & 96 & 120 & 144 \\
\cline { 2 - 8 } & 2 & 30 & 60 & & & & \\
\cline { 2 - 8 } & 6 & 36 & & & & & \\
\cline { 2 - 8 } & 8 & 42 & & & & & \\
\cline { 2 - 8 } & 12 & & & & & & \\
\cline { 2 - 8 } & 18 & & & & & & \\
\hline
\end{tabular}

\section{RESULTS AND DISCUSSION}

\section{Optimization of Variables}

Considering that both $\mathrm{C}_{18}{ }^{5-8}$ and Oasis $\mathrm{HLB}^{12}$ has been considered as sorptive phases in the determinations of these analytes using SPE, providing both good analytical performance, these same sorbents were preliminarily tested in RDSE for the extraction of both target compounds. It was observed that both sorbents provided high and comparable retention of the analytes in plasma, considering the $\mathrm{pH}$ range $3-5$. However, a high variability in the retention of TCB-SO $\mathrm{SO}_{2}$ was observed in $\mathrm{C}_{18}$, with relative standard deviation over $40 \%$ in the $\mathrm{pH}$ range studied. Taking this into account, Oasis HLB was the selected phase for this study, showing in this prelimirary experiment a better reproducibility.

Taking into account our previous experiences in RDSE procedures, ${ }^{13,14,18,19}$ the rotation velocity of the disk was kept at $2000 \mathrm{rpm}$, and all the optimization was made in absence of matrix modifiers. Rotation velocity was kept at the maximum velocity achieved by the magnetic stirrer, because under this condition the boundary layer formed on the surface of the sorptive phase decreases and analyte mass transfer is faster. Matrix modifiers were avoided, because these compounds are of intermediate polarity, and consequently the probability of adsorption on the walls of the sample container is low, together with a predictable minor effect of ion strength on the extraction efficiency. Intermediate polarity was also a reason to select the sorbent, considering also that some studies made by SPE used Oasis HLB as sorptive phase. ${ }^{9}$

Using a multivariate experimental design, the optimization of sample dilution factor and $\mathrm{pH}$ was performed. Optimization was performed using blank plasma samples spiked with a concentration of $2.5 \mu \mathrm{gmL}^{-1}$ of TBC$\mathrm{SO}$ and $\mathrm{TBC}-\mathrm{SO}_{2}$. The recoveries of both compounds were used as response. As can be seen in Pareto charts (Fig. 3a), sample dilution shows a significant positive effect, and the increase of $\mathrm{pH}$ shown also a significant effect, but negative. When the slopes of the main effect plots (Fig. 3b) are analyzed, it is possible to observe that at $\mathrm{pH} 3$ the signals tend to a maximum constant value. Plots also shows that dilution has an important effect on the recoveries, and the maximum response obtained, inside of the studied range, is 10. However a 
value of 20 was selected (corresponding to $400 \mu \mathrm{L}$ of sample) because it provides an adequate recovery for the range of concentration normally found in plasma for pharmacokinetics studies.

(a)

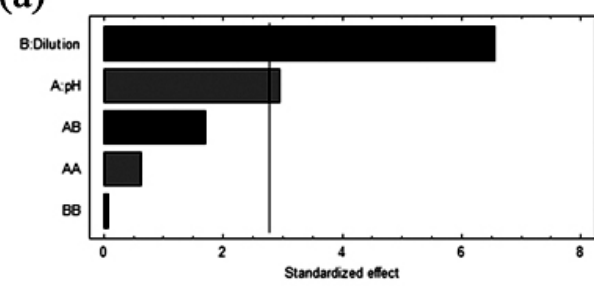

Standardized Pareto Chart for TCB-SO

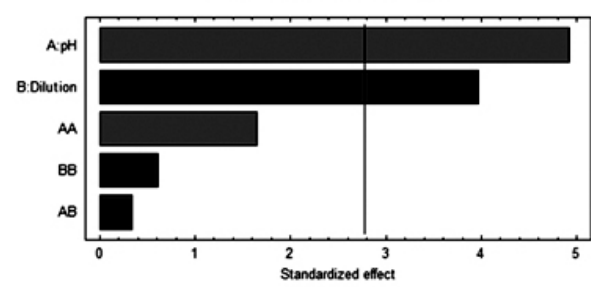

(b)
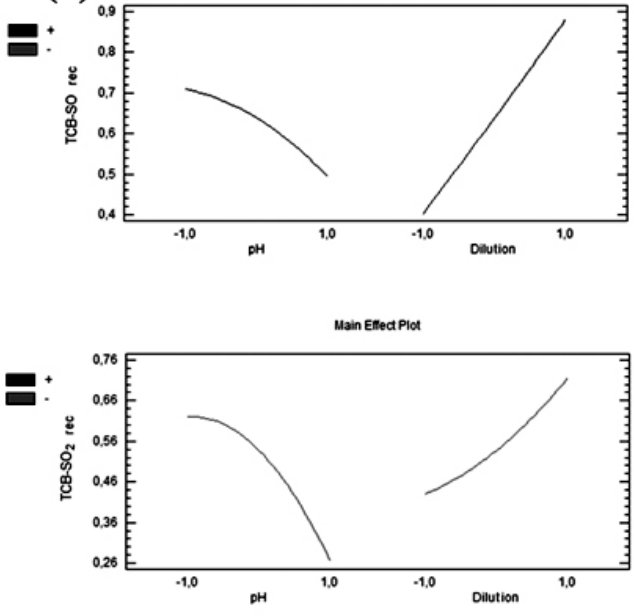

Fig. 3. (a) Pareto charts showing the effect of $\mathrm{pH}$ and sample dilution on extraction process for TCB-SO and TCB-SO2 in cattle plasma. (b) Main effect plots of $\mathrm{pH}$ and sample dilution on extraction process of TCB-SO and TCB-SO2 in cattle plasma.

The extraction profile of each metabolite was then assessed under the selected variables of the method (Fig. 4). As can be seen, extraction equilibrium time is achieved at 90-100 min, approximately.

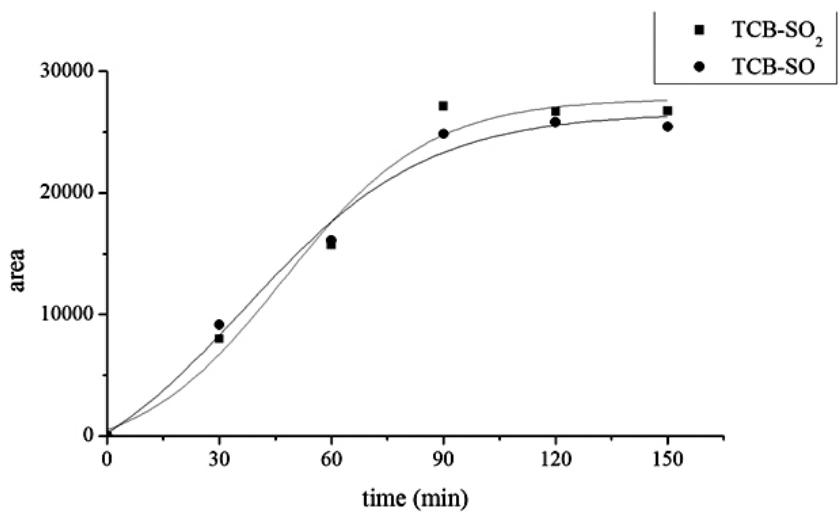

Fig. 4. Extraction profile for TCB-SO and $\mathrm{TCB}-\mathrm{SO}_{2}$ in plasma $(2.5$ $\mu \mathrm{gmL}^{-1}$ ) using RDSE.

Regarding to desorption of TCB-SO and TBC-SO from the rotating disk, acetone was selected as the solvent. Normally methanol had been selected in previous studies with RDSE, in environmental samples such as waters, but in the present case, elution with methanol presented a higher chromatographic noise than the observed with acetone when a blank plasma was analyzed. A complete elution of both metabolites was obtained with of $8 \mathrm{~mL}$ of acetone at a rotation velocity of the disk of $1400 \mathrm{rpm}$ for $60 \mathrm{~min}$.

Fig. 5 shows the HPLC chromatograms obtained when a standard and a sample extract containing TBC-SO and TBC-SO $\mathrm{SO}_{2}$ at a concentration of 2.5 $\mu \mathrm{gmL}^{-1}$ were injected. As can be seen, the signals are well resolved and no interference from the matrix are evidenced. Retention times of approximately 10 and 12 min were obtained for TBC-SO and $\mathrm{TBC}-\mathrm{SO}_{2}$, respectively, with a total chromatographic run of $13 \mathrm{~min}$.

\section{Analytical Features of the Method}

Following the recommendations given in the VICH GL02 and VICH GL49 guides, ${ }^{15,16}$ the validation of the method was performed. Table 2 shows the analytical features of the method. For both target compounds, a very good linearity was obtained $(\mathrm{R}>0.99)$ in both cases; when the analytes are present in standards and in spiked samples. The method resulted also selective and sensitive enough to measure the concentration levels found in plasma sample in pharmacokinetic studies. According to Table 2, a very good accuracy and precision of the method were also achieved.

\section{Application in a Pharmacokinetic Study}

Pharmacokinetic studies are mandatory to establish that release of the drug is optimum for the desired dose or if is necessary to use prolonged periods of drug release. In this context, the proposed analytical method was applied to determine the pharmacokinetic in cattle plasma after the administration of a commercial product of TCB $(10 \% \mathrm{p} / \mathrm{v})$ by measuring the concentration of its metabolites TBC-SO and TBC-SO in the plasma of the animals. Fig. 6 shows the curves obtained after analysis of 192 samples (16 different time points after administration to 12 cattles) considering both TCB formulations. The pharmacokinetics data obtained from TCB in plasma are consistent with the data reported in the literature, ${ }^{20-22}$ and the pharmacokinetic parameters for both formulations were similar, as can be seen in Table 3. No significant differences were observed between $\mathrm{C}_{\max }$ y $\mathrm{ABC}_{0-\mathrm{t}}(\mathrm{p}$ values $>0.05$ ), obtained for both formulations, consequently both pharmaceutical products can be considered bioequivalent. 

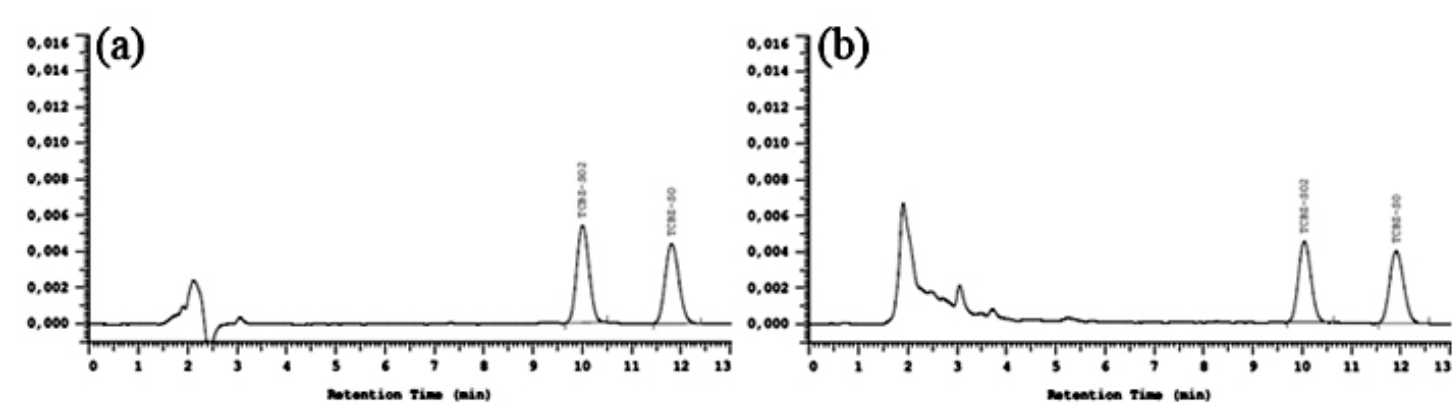

Fig. 5. Chromatograms of (a) standards of TCB-SO and TCB-SO $\left(0.5 \mu \mathrm{gmL}^{-1}\right)$, ( b ) Cattle plasma samples spiked with TCB-SO and TCB-SO $2\left(2.5 \mu \mathrm{gmL}^{-1}\right)$.

Table 2. Analytical features calculated according to guides VICH GL02 and VICH GL49.

\begin{tabular}{|c|c|c|c|c|}
\hline Analytical Feature & $\begin{array}{c}\text { Concentration } \\
\text { level }\end{array}$ & Replicates & TCB-SO & TCB-SO 2 \\
\hline Linearity of standards & 5 & 3 & $\begin{array}{c}\mathrm{y}=66176 \mathrm{x}-3638 \\
\mathrm{R}^{2}=0.999\end{array}$ & $\begin{array}{c}y=72358 x-4850 \\
R^{2}=0.997\end{array}$ \\
\hline Linearity of spikes & 5 & 3 & $\begin{array}{c}y=11512 x-1641 \\
R^{2}=0.996\end{array}$ & $\begin{array}{c}y=10973 x-1763 \\
R^{2}=0.996\end{array}$ \\
\hline Selectivity & 1 & 6 & $11.8 \%$ & $3.4 \%$ \\
\hline $\begin{array}{l}\text { Limit of Quantitation } \\
\text { (LOQ) }\end{array}$ & 5 & 3 & $108.4 \mathrm{ngmL}^{-1}$ & $104.5 \mathrm{ngmL}^{-1}$ \\
\hline $\begin{array}{l}\text { Limit of Detection } \\
\text { (LOD) }\end{array}$ & 5 & 3 & $35.8 \mathrm{ngmL}^{-1}$ & $34.5 \mathrm{ngmL}^{-1}$ \\
\hline Accuracy & 3 & 3 & $\begin{array}{l}(\text { low })+10.0 \% \\
\text { (medium) }-8.7 \% \\
\text { (high) }-8.1 \%\end{array}$ & $\begin{array}{c}\text { (low) }-7.7 \% \\
\text { (medium) }-16.7 \% \\
\text { (high) }-15.0 \%\end{array}$ \\
\hline Precision & 3 & 3 & $\begin{array}{c}\left(\mathrm{CV}_{\text {low }}\right) 8.1 \% \\
\left(\mathrm{CV}_{\text {medium }}\right) 5.5 \% \\
\left(\mathrm{CV}_{\text {high }}\right) 6.8 \%\end{array}$ & $\begin{array}{c}\left(\mathrm{CV}_{\text {low }}\right) 8.0 \% \\
\left(\mathrm{CV}_{\text {medium }}\right) 4.1 \% \\
\left(\mathrm{CV}_{\text {high }}\right) 8.0 \%\end{array}$ \\
\hline
\end{tabular}
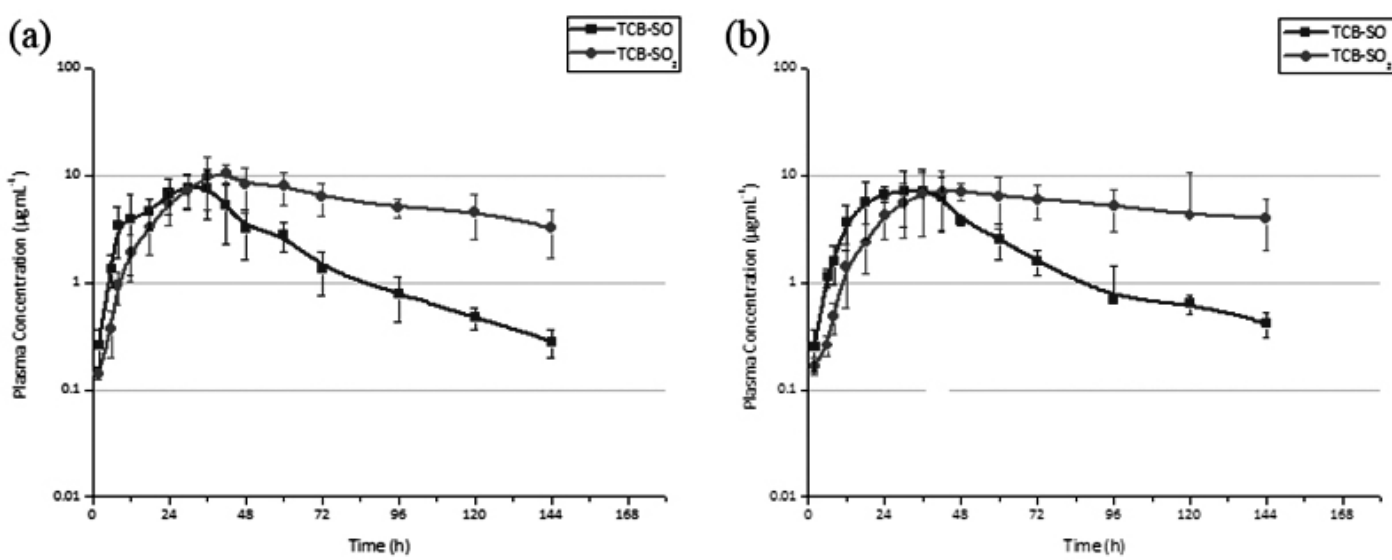

Fig. 6. Pharmacokinetics of two veterinary products of $10 \%$ triclabendazole (oral administration). (a) Trisuvet (Veterquimica S.A.) and ( $\mathrm{b}$ ) Commercial Product. ( $\mathrm{n}=6$ for both products).

When a critical comparison between the developed method with its counterparts using SPE, ${ }^{6-8}$ the main advantage of the present RDSE methodology is its simplicity and low-cost involved in the extraction device used. Regarding LOD, both alternatives resulted similar, as well as the ecoefficiency (excellent green analysis) as can be seen in Table 4 and Table 5. The main drawback of the present method was the time involved in the extraction process, which is longer than the used in SPE (150 vs $50 \mathrm{~min})$.

\section{CONCLUSIONS}

An analytical method based on RDSE and HPLC was developed and validated for the microextraction of the antiparasitic triclabendazole metabolites in cattle plasma matrix. The method developed is useful for bio-equivalence studies or to evaluate the pharmacokinetic effect of different formulations. The simplicity, economy and good performance of the process, make it interesting for alternative use in routine laboratories. 
Table 3. Pharmacokinetic parameters obtained for TCB -SO cattle plasma levels, for two veterinary $10 \%$ Triclabendazole products. (a) Trisuvet $10 \%$, Veterquímica S.A. and (b) other commercial product, both in doses of $12 \mathrm{mgkg}^{-1}$ in oral bolus.

\begin{tabular}{|c|c|c|c|c|c|c|}
\hline \multirow{2}{*}{$\begin{array}{c}\text { Pharmacokinetic } \\
\text { parameters of TCB-SO }\end{array}$} & \multicolumn{3}{|c|}{ Trisuvet 10\% } & \multicolumn{3}{c|}{ Commercial formulation } \\
\cline { 2 - 7 } & $\overline{\mathrm{x}}$ & $\sigma$ & $\mathrm{CV}$ & $\overline{\mathrm{x}}$ & $\sigma$ & $\mathrm{CV}$ \\
\hline $\mathrm{C}_{\max }\left(\mu \mathrm{gmL}^{-1}\right)$ & 9.7 & 1.5 & 15.8 & 8.8 & 2.8 & 32.2 \\
\hline $\mathrm{C}_{\min }\left(\mu \mathrm{gmL}^{-1}\right)$ & 0.3 & 0.1 & 45.7 & 0.4 & 0.1 & 26.2 \\
\hline $\mathrm{T}_{\max }(\mathrm{h})$ & 36.0 & 9.3 & 25.8 & 36.0 & 7.6 & 21.1 \\
\hline $\mathrm{ABC}_{0-\mathrm{t}}\left(\mu \mathrm{gmL} \mathrm{m}^{-1}\right)$ & 408.8 & 85.7 & 21.0 & 410.6 & 91.5 & 22.3 \\
\hline $\mathrm{ABC}_{0-\infty}\left(\mu \mathrm{gmL}^{-1} \mathrm{~h}^{-1}\right)$ & 420.0 & 90.7 & 21.6 & 441.3 & 101.2 & 23.2 \\
\hline
\end{tabular}

$=$ average; $\sigma=$ standard deviation; $\mathrm{CV}=$ coefficient of variation; $\mathrm{C}_{\max }=$ maximum concentration; $\mathrm{C}_{\min }=$ minimum concentration; $\mathrm{T}_{\max }=$ time to reach maximum concentration; $\mathrm{ABC}_{0-\mathrm{t}}=$ area under the curve from time 0 to the last measurement; $\mathrm{ABC} \mathrm{C}_{0-\infty}=$ area under the curve from time 0 extrapolated to infinity.

Table 4. Comparison of analytical and efficiency parameters for RDSE and SPE method.

\begin{tabular}{|c|c|c|}
\hline Parameters & RDSE method & SPE method $(7,8)$ \\
\hline & $35.8(\mathrm{TCB}-\mathrm{SO})$ & $15.0(\mathrm{TCB}-\mathrm{SO})$ \\
LOD $\left(\mu \mathrm{gmL}^{-1}\right)$ & $34.5\left(\mathrm{TCB}-\mathrm{SO}_{2}\right)$ & $23.0\left(\mathrm{TCB}-\mathrm{SO}_{2}\right)$ \\
\hline & $91.3(\mathrm{TCB}-\mathrm{SO})$ & $90.9(\mathrm{TCB}-\mathrm{SO})$ \\
Recovery $(\%)$ & $83.3\left(\mathrm{TCB}-\mathrm{SO}_{2}\right)$ & $79.9(\mathrm{TCB}-\mathrm{SO})_{2}$ \\
\hline & $5.5(\mathrm{TCB}-\mathrm{SO})$ & $4.1(\mathrm{TCB}-\mathrm{SO})$ \\
\hline CV $(\%)$ & $4.1\left(\mathrm{TCB}^{\left.-\mathrm{SO}_{2}\right)}\right.$ & $5.9\left(\mathrm{TCB}-\mathrm{SO}_{2}\right)$ \\
\hline Sample process time $(\mathrm{min})$ & $\cong 150$ & $\cong 50$ \\
\hline Analytical Eco-Scale score & 87 & 82 \\
\hline
\end{tabular}

Table 5. Detailed information about the penalty points (PP) and eco-scale score for RDSE and SPE method (21).

\begin{tabular}{|c|c|}
\hline RDSE method & SPE method $(7,8)$ \\
\hline \multicolumn{2}{|c|}{ Reagents } \\
\hline $\begin{array}{l}\text { Methanol: Re-used, }<1 \mathrm{~mL} \text { per sample } \\
\text { (4 PP) }\end{array}$ & Methanol: $7.5 \mathrm{~mL}$ (8 PP) \\
\hline Acetone: $8 \mathrm{~mL}$ (4 PP) & Acetone: $1 \mathrm{~mL}$ (4 PP) \\
\hline Water: $15 \mathrm{~mL}(0 \mathrm{PP})$ & Water: $15 \mathrm{~mL}(0 \mathrm{PP})$ \\
\hline \multicolumn{2}{|c|}{ Instrumental } \\
\hline Stirrer (1 PP) & Vacuum for manifold (2 PP) \\
\hline HPLC-UV (1 PP) & Centrifuge (1 PP) \\
\hline Waste (3 PP) & HPLC-UV (1 PP) \\
\hline \multirow[t]{2}{*}{ Risk (0 PP) } & Waste (3 PP) \\
\hline & Risk (0 PP) \\
\hline Sum $P P=13$ & Sum $P P=19$ \\
\hline Analytical Eco-Scale total score $=87$ & $\begin{array}{c}\text { Analytical Eco-Scale total score } \\
=81\end{array}$ \\
\hline
\end{tabular}

\section{ACKNOWLEDGEMENTS}

The authors thank to FONDECYT (Grants numbers 1140716 and 7813110007) for financial support. One of the authors (AC) would like to thank to CONICYT the doctoral fellowship 21120020.

\section{REFERENCES}

1. Bennett J., Köhler P. Exp. Parasitol. 63, 49, (1987).

2. Hennessy D.R., Lacey E., Steeel J.W., Prichard R.K. J. Vet. Pharmacol. Ther. 10, 64, (1987).

3. Virkel G., Lifschitz A., Sallovitz J., Pis A., Lanusse C. J. Vet. Pharmacol. Ther. 29, 213, (2006). 
4. Arnorld D. (2012) Addendum to the monographs prepared by the 40th, 66th and 70th Meetings of the Committee and published in FAO Food \& Nutrition Paper 41/5 \& FAO JECFA Monographs 2 and 6, respectively. 1-75, Webpage visited at 10th May 2016. ftp://ftp.fao.org/ag/agn/jecfa/ vetdrug/12-2012-triclabendazole.pdf

5. Bull M.S., Shume G.R.E. J. Pharm. Biomed. Anal. 5, 527, (1987).

6. Sanyal P.K. Ind. J. Pharmacol. 26, 200, (1994).

7. Formentini E.A., Mestorino N., Pesoa J.M., Lucas M., Reggiardo E., Marti-Diaz M., Reutemann S.H., Errecalde J.O. Rev. FAVE - Cienc. Vet. 3, 39, (2004)

8. Mestorino N., Formentini E.A., Lucas M.F., Fernandez C., Modamio P., Mariño-Hernández E., Errecalde J.O. Vet. Res. Commun. 32, 21, (2008).

9. Cai Ch., Xue F., Wang Z., Xiao S., Zhang L. Food Anal. Methods 5, 1260, (2012).

10. Cai Ch., Zhang L., Xue F., Qiu M., Zheng W. J. Chromatogr. B 878, 3106 , (2010).

11. Belal F., El-Din M.K.Sh., Elenany N., Saad S. Luminescence 29, 559 , (2014).

12. Zrnčić M., Gros M., Babić S., Kaštelan-Macan M., Barcelo D., Petrović M. Chemosphere 99, 224, (2014).

13. Cañas A., Valdebenito S., Richter P. Anal. Bioanal. Chem. 406, 2205,
(2014).

14. Manzo V., Honda L., Navarro O., Ascar L., Richter P. Talanta 128, 486, (2014).

15. Validation of Analytical Procedures: Methodology: Final Guidance VICH GL2 (1998) 1-10 Webpage visited at 10th May 2016. http://www.fda. gov/downloads/AnimalVeterinary/GuidanceComplianceEnforcement/ GuidanceforIndustry/UCM052379.pdf

16. Validation of Analytical Methods Used in Residue Depletion Studies VICH GL49 (2015) 1-23. Webpage visited at 10th May 2016. http://www. fda.gov/downloads/AnimalVeterinary/GuidanceComplianceEnforcement/ GuidanceforIndustry/UCM207942.pdf

17. Good Clinical Practice. VICH GL9 (2000) 1-31. Webpage visited at 10th May 2016. http://www.fda.gov/downloads/AnimalVeterinary/ GuidanceComplianceEnforcement/GuidanceforIndustry/UCM052417.pdf

18. Richter P., Cañas A., Muñoz C., Leiva C., Ahumada I. Anal. Chim. Acta. 695, 73, (2011).

19. Jachero L., Sepúlveda B., Ahumada I., Fuentes E., Richter P. Anal. Bioanal. Chem. 405, 7711, (2013).

20. Blahová E., Brandšteterová E. Chem. Pap. 58, 362, (2004).

21. Gałuszka A., Konieczka P., Migaszewski Z.M., Namiesnik J. Trends Anal. Chem. 37, 61, (2012). 